\title{
Mulheres artistas e Autorretrato: a representação de si como sujeito
}

\author{
Thiane Nunes ${ }^{1}$ \\ DOI 10.20396/eha.vil4.3388
}

Há mais de três décadas que pesquisadoras têm investigado o papel da mulher artista e a frequente marginalização da sua presença na historiografia, nos espaços de exposição e nos debates estéticos da arte ocidental. Através de uma abordagem sócio-política da arte, reconhecemos que elas estão ausentes como autoras, nos museus e galerias, porém estiveram sempre presentes nas representações, como objeto, tema, alegoria, musas, bem como em infinitas reproduções de nudez.

$\mathrm{O}$ artigo Virility and Domination in Early Twentieth-Century Vanguard Painting, de Carol Duncan, aponta para uma longa história na qual a representação do corpo feminino foi persistentemente apresentada como um local de prazer visual masculino. Em contrapartida, artistas contemporâneas, principalmente a partir dos anos 1970, mediadas pelo suporte de novas temáticas surgidas a partir do século XX (como dor, sexualidade, raça e gênero), começaram a buscar novas e diferentes interpretações de seus próprios corpos, de seu olhar e lugar no mundo, voltando-se para o corpo feminino como proposição principal de suas experiências².

Trabalhar sob uma perspectiva social da arte vai inevitavelmente nos direcionar para questões de presenças e ausências, e demandas que abrangem os diferentes regimes de representação. Um recorte da minha pesquisa acaba por se concentrar na ideação sexista dos corpos femininos, e, finalmente, na autorrepresentação criada pelas próprias artistas, quando finalmente esse corpo representado tem algo de biográfico, quando passa a se considerar sujeito - e não apenas um objeto de deleite do olhar masculino. Ao olhar para essas produções me pareceu possível ensaiar alguns termos de uma história do autorretrato feminino. Para isso, é de extrema importância tomar conhecimento de tais obras e ter acesso a esses trabalhos, tendo em vista a contribuição que tantas

\footnotetext{
1 Thiane Nunes é Doutoranda em Artes Visuais, com ênfase em HTC pelo PPCAV-UFRCS/CAPES. Atualmente desenvolve tese que analisa a misoginia, o patriarcado cultural e a invisibilidade da mulher artista, com interesse em registros historiográficos e revisionismo, em especial no período que compreende as Vanguardas Históricas e os modernismos díspares. É membro do projeto de extensão e grupo de estudos Feminismo e História da Arte (UFRCS). Trabalha sob uma perspectiva social e feminista da arte, apontando questionamentos em relação ao cânone e praticando a perturbação dos discursos e narrativas feitas pela historiografia oficial. Pesquisa as questões de presenças e ausências na arte, bem como os diferentes regimes de representação. Possui livro, traduções, entrevistas e artigos publicados, no país e exterior. http://lattes.cnpq. br/6863554229175795

2 DUNCAN, 1982, p. 293-315.
} 
artistas fizeram a respeito da imagem da mulher. $\mathrm{O}$ fato de que podemos testemunhar a maneira que essas artistas se enxergavam, dezenas ou centenas de anos atrás, num mundo onde questões sociais e a própria arte foi amplamente dominada por uma cultura patriarcal, é revelador, não apenas do poder dessas imagens, mas também nos termos de comparação com o gênero do autorretrato contemporâneo, que segue hoje renegociando os códigos de feminilidade e representação do corpo feminino.

Questão de gênero

Artistas abordaram as questões da diferença dentro do termo 'mulher', por meio de uma exploração da autoimagem que confronta estereótipos e proclama uma nova presença. Após uma extensa pesquisa e apreciação desta iconografia específica, foi impossível conceituar qualquer uma dessas obras tomando os termos básicos de 'bom' ou 'ruim' ou 'excelente'. Como historiadora, tais classificações me pareceram menos interessantes do que o fato de que esses rostos femininos sinalizavam um afastamento radical da norma e eram, portanto, suficientes para impedir que as imagens fossem lidas da mesma forma que posso ler o gênero do autorretrato masculino.

Tentei dar sentido ao que estava vendo tratando os autorretratos como versões pintadas de autobiografias, uma maneira de a artista apresentar uma história sobre si mesma. A autobiografia pode ser baseada em fatos, mas a necessidade do autor de contar um conto confiável e compreensivo torna o produto final tão engenhoso quanto um romance. O espectador de um autorretrato deve poder ler o vocabulário de pose, gesto, vestimentas, mobiliário, acessórios, local, expressão facial, verificando-o de acordo com as ideias de sua época. Tomando essas imagens a sério perguntei-me por que elas haviam escolhido se retratar dessa ou de outra maneira. Também questionei se seria inapropriado prever a franqueza dos autorretratos de hoje na arte das mulheres do passado.

Como já explorado por diversas historiadoras da arte, é fato que na maior parte dos países ocidentais foi vetado por muito tempo o ingresso das mulheres às academias de arte, dificultando a aquisição de conhecimentos primordiais na sua formação e experiência, principalmente no que tange a questão do estudo de modelo vivo e do nu. Mesmo nos ateliês particulares, não seria de bom tom para as moças, que teriam assim excluídas as competências necessárias para uma plena representação dos corpos humanos.

Lidar com tantas restrições era difícil, desde os estereótipos femininos a opiniões paternalistas sobre as habilidades das mulheres. Ainda hoje o artista masculino pode ser visto, como o gênio 
excêntrico, o fora da lei ou o místico. As biografias escritas por Vasari são repletas de exemplos estranhos, como no caso de Piero di Cosimo, que tinha medo de fogo e por isso era crudívoro, a exceção de ovos, que comia quarenta todos de uma só vez, cozidos junto - nas mesmas panelas -com suas colas e tintas. Retraído e misógino, não gostava de conviver com mulheres. Esse fascínio pelo artista como um mito ou um não-conformista continuou no século XIX com a aparição do boêmio e do flâneur.

Tipos artísticos femininos são menos divertidos, e enfatizam o fato de que uma artista feminina era tanto uma artista desviante quanto uma mulher desviante, vista como, na melhor das hipóteses, pretensiosa e, na pior das hipóteses, uma bizarra transgressora da feminilidade. Ela fica no cavalete perdendo grampos de cabelo pelos punhados e se levando ridiculamente a sério, dada a qualidade de segunda classe de seu trabalho. Ou ela era vista como um prodígio (que tem conotações monstruosas e de exceção), como sexualmente suspeita (não é metade tão positiva quanto um boêmio), ou como uma amadora (que codifica a ideia de segundo nível).

O mito da criança prodígio figura em grande parte nas biografias de artistas masculinos, como no caso de Cimabue tropeçando no jovem Giotto, esboçando um desenho de uma ovelha com uma pedra. O talento de um menino também poderia demonstrar poderes quase miraculosos quando como Filippo Lippi tinha dezessete anos, ao ganhar sua liberdade dos mouros desenhando o retrato de seu captor. Ou um menino talentoso é aprendiz de um mestre famoso, garantindo assim a continuação da patrilinhagem ${ }^{3}$. O brilho da infância nas biografias de mulheres artistas tem um toque ligeiramente diferente, apontando para as verdades sociais que estão por trás do mito. Não há relatos de descobertas de jovens talentos femininos por pintoras consagradas, o que não surpreende, uma vez que críticos e historiadores tendem a ver mulheres artistas como aberrações isoladas da natureza, em vez de um elo de uma cadeia de artistas mulheres. O padrão professora -aluna também está ausente. No final do século 18, algumas das principais artistas mulheres precisavam de um mentor masculino para apresentá-la ao mundo da arte. A versão feminina do mito do talento infantil é mais simples, uma questão de notar que a artista teve acesso a arte desde muito jovem. Anna Waser orgulhosamente inscreveu a informação que ela tinha doze anos em seu autorretrato de 1691 (FIG. 1).

Esse mundo paralelo afetou os autorretratos das mulheres. Como membro minoritário da profissão, com treinamento deficiente, ciente de que suas obras seriam examinadas de forma mais

3 Patrilinhagem na arte é assunto de um artigo de 1991, de Mira Schor. 
severa que as dos retratistas masculinos, uma artista deveria pensar muito sobre a apresentação de si mesma. Produzir um autorretrato significava reconciliar o conflito entre o que a sociedade esperava das mulheres e o que esperava dos artistas. O problema para as mulheres - e também o desafio - era que os dois conjuntos de expectativas eram diametralmente opostos. A resposta foi uma defensiva criativa. É somente compreendendo o desejo das mulheres de superar a crítica, antecipando suas respostas, que se pode começar a entender por que seus autorretratos se parecem com o que vemos.

\section{Algumas pioneiras}

Embora os autorretratos de mulheres artistas antes do século XX possam parecer incomuns, eles não são raros. Ao procurá-los, nos deparamos com uma enorme galeria de mulheres pintoras empunhando seus pincéis, mostrando seus quartos e locais de trabalho, segurando suas paletas e encarando seu olhar. Diferente do que muitos pensariam, elas produziram muita autorreflexão: é possível citar Sofonisba Anguissola, por exemplo, que pinta uma das mais longas séries de autorretratos, da adolescência à velhice, em plena Itália do século XVI. Um autorretrato intitulado L'Auteur à ses occupations e datado de 1789 mostra Marie-Nicole Vestier Dumont com paleta na mão e o filho em seu berço, demonstrando assim seu duplo papel, de mãe e artista (FIC. 2). Entretanto, somente após o século XIX é que as mulheres puderam começar a adotar, com cautela, a figura pública de artista. Em 1825, Hortense Haudebourt-Lescot tornou-se a primeira mulher na arte ocidental a ousar mostrar-se usando uma boina característica da profissão, além de uma corrente de ouro como símbolo de seu status profissional.

É surpreendente a variedade e originalidade das obras que podemos encontrar. São imagens que nos desafiam a considerar a evidência de que os autorretratos das mulheres são diferentes daqueles produzidos pelos homens - e são mais interessantes do que a historia tradicional e um olhar pouco treinado ou apressado poderia sugerir. Chamam a atenção para particularidades diferentes das produções de seus colegas homens, já que não são reflexões inocentes do que os artistas veem quando se olham no espelho. Essas imagens fazem parte da linguagem que artistas usam para estabelecer um registro, desde o simples 'é assim que eu me pareço' até o mais complexo 'é nisso que eu acredito'.

Artistas se autorretrataram porvárias razões: para mostrar suas habilidades, como o espanhol do Meléndez exibindo orgulhosamente seu domínio do desenho da vida; para se vangloriar de 


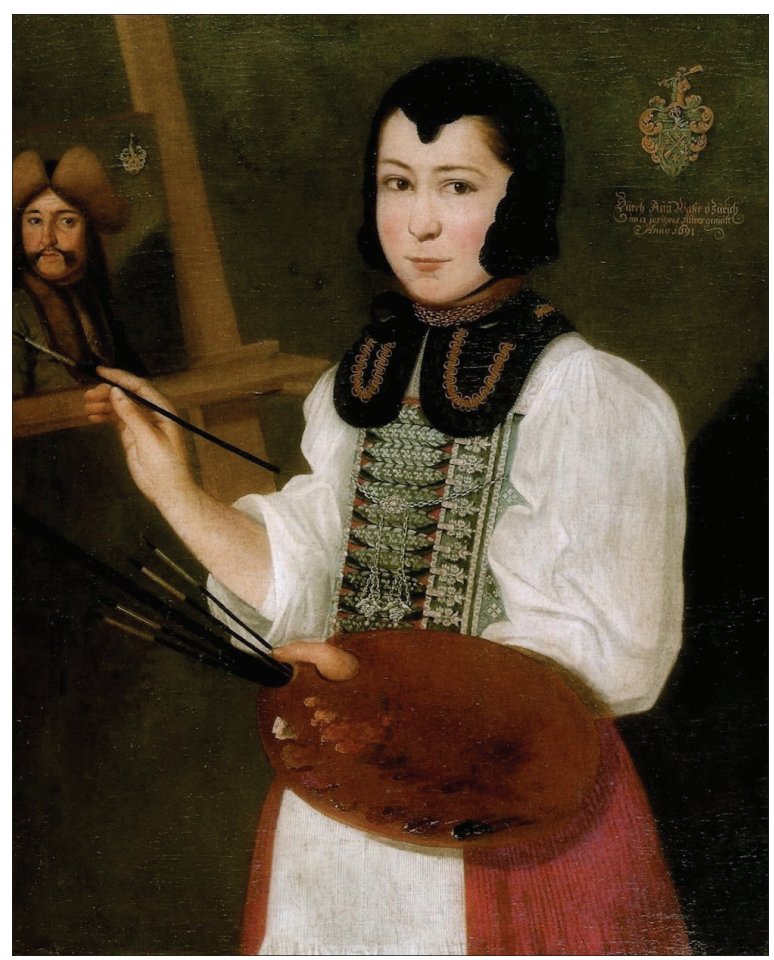

[Figura 01] Anna Waser. Autorretrato. 1691.

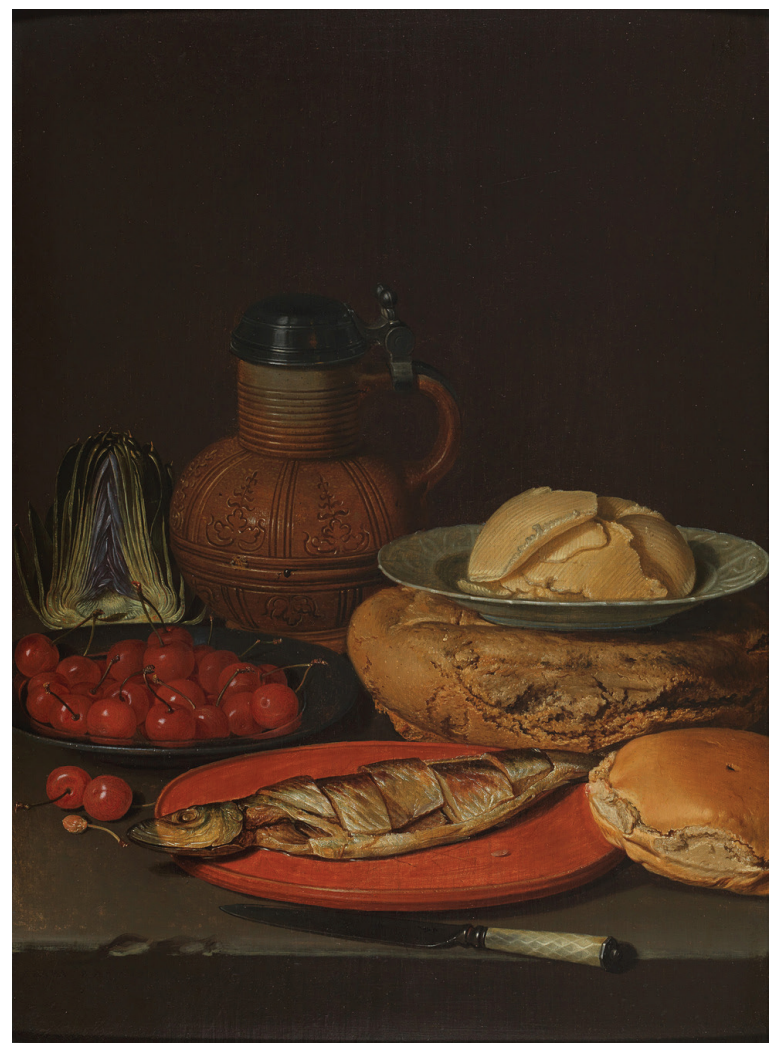

[Figura 03] Clara Peeters. Natureza morta com arenque, cerejas, alcachofra, jarro e prato com manteiga. 1612. O reflexo da artista está na parte escura do bojo da jarra, e uma rubrica é inserida no aço da faca.

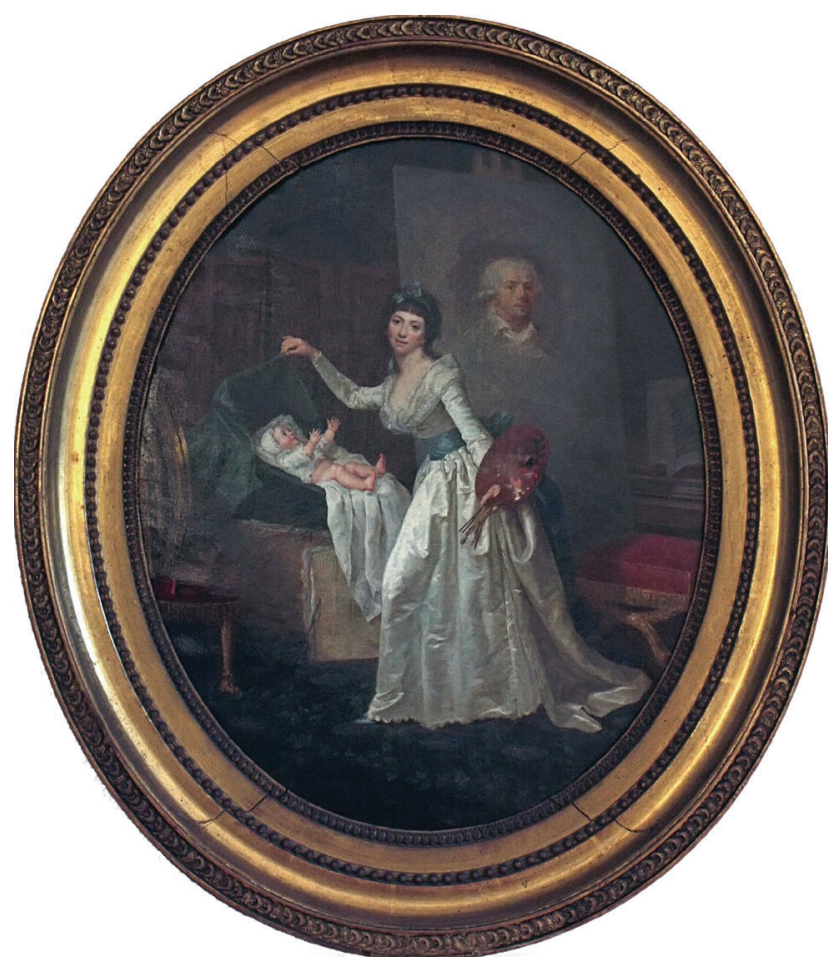

[Figura 02] Marie-Nicole Vestier Dumont. L'Auteurà ses occupations. 1789.

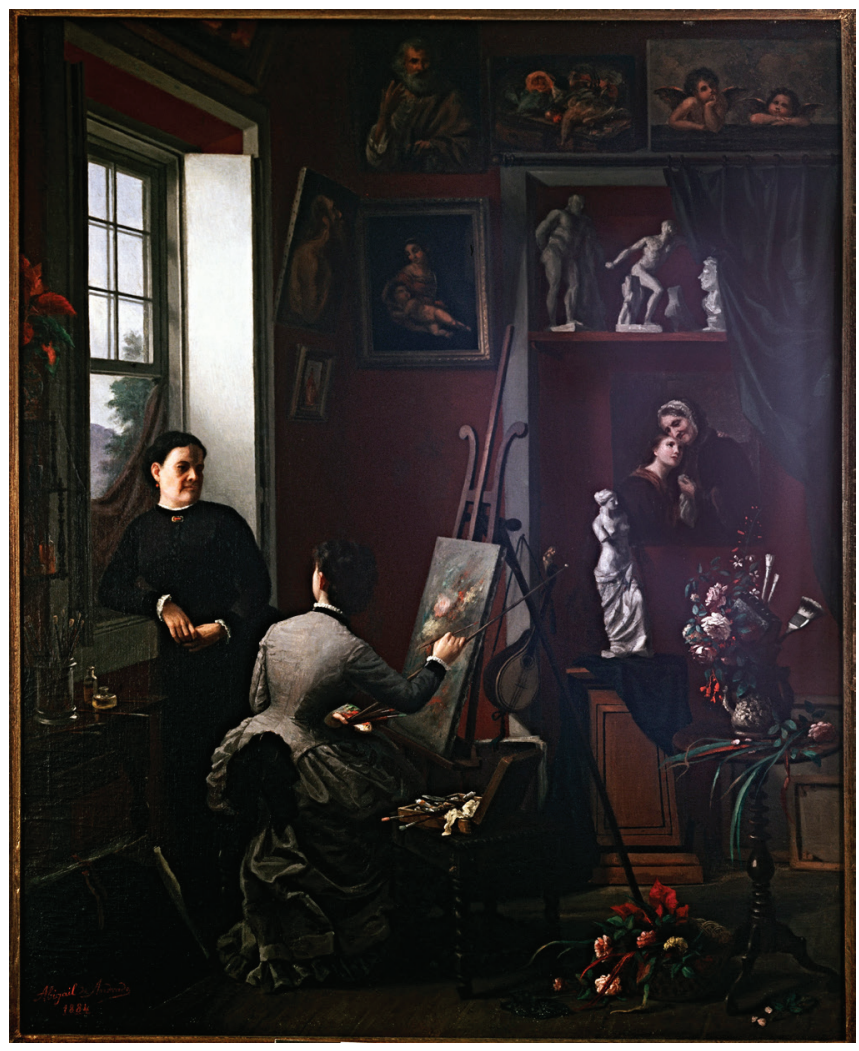

[Figura 04] Abigail de Andrade. Interior de Ateliê. 1884. Coleção particular (Hecilda e Sérgio Fadel), Rio de Janeiro. 
seu status, como Joshua Reynolds se pintando em suas vestes como Doutor em Filosofia depois de ter sido honrado pela Universidade de Oxford em 1773; para imitar mestres do passado, como Rembrandt em 1640, baseando sua pose em um retrato de Ticiano, para divulgar suas próprias crenças artísticas, como Baccio Bandinelli segurando um desenho de Hércules para mostrar seu respeito pela escultura clássica.

Algumas questões podem ser levantadas a partir da comparação entre os gêneros: Por que tantas mulheres artistas se apresentavam de maneira mais moderada, tão menos dramática? Por que as mulheres raramente se gabavam de suas habilidades? Muitas das diferenças pareciam estar relacionadas ao tempo. As imagens maternas tendiam a se agrupar no final do século XIX; as imagens musicais foram fortes no século XVI. Mas existem obras que parecem não ter nenhum equivalente masculino, como em uma representação de Artemisia Centileschi de si mesma como a personificação da pintura, ocasião em que dá vazão a um tipo de autorretrato que nenhum homem poderia habitar.

Estratégias para garantir a perpetuação de autoria também eram utilizadas engenhosamente pelas artistas. É sabido hoje que muitas obras de mulheres acabavam sendo vendidas no mercado de arte com sua assinatura removida, substituída por outra, masculina, como forma de garantir uma venda mais evidente. É instigante o extraordinário caso dos selfs secretos da pintora belga Clara Peeters, nascida no século XVI, conterrânea de Antoon van Dyck. Clara dava um jeito de incluir sua própria assinatura em suas naturezas mortas, um dos gêneros mais aceitáveis para uma mulher pintar. Em algumas telas, seu nome surge cravado na lateral da figura fálica de uma faca, que normalmente aponta para algum outro elemento, como alcachofras, ou romãs, ou figos, que partidos ao meio, lembram, de forma não menos fascinante, uma genitália feminina. Além disso, se autorretratava em pequenos detalhes nos quadros, na face espelhada de uma taça, na tampa refletora de uma jarra, de forma que passaram despercebidos por séculos enquanto expostos sem alarde em algum museu europeu ou esquecidos em acervos (FIC. 3).

Era uma maneira que ela encontrava para se autoafirmar como mulher e artista, para garantir que seria conhecida no futuro, ou, quem sabe, ironizando o fato de que os compradores de suas obras podem ter morrido sem nunca terem percebido que penduravam um autorretrato de uma artista mulher na parede de casa. No Brasil, onde as mulheres só adentraram na academia após a Proclamação da República, temos poucas pioneiras do gênero antes do advento modernista. No entanto, chama a atenção uma peculiar obra de Abigail de Andrade (1864-1890), Interior de Ateliê, em que se retrata no exercício da profissão, pintando um vaso com flores enquanto conversa com a 
figura de outra mulher, que aparece em pé numa janela, no ponto esquerdo onde a tela se ilumina. Para Ana Paula Cavalcanti Simioni, a posição da artista, de costas para o espectador, negaria sua identidade ${ }^{4}$. Entretanto, me parece que se há algo a ser negado, é a maneira habitual de ser vista: não está posando como um corpo atrativo para o olhar masculino, preferindo se retratar como uma artista, imune ao olhar masculino (FIG. 4).

Modernas, num mundo nem tanto

Uma grande mudança veio com o século $X X$, com um novo tipo de mulher, mais independente e livre das noções convencionais de comportamento feminino. Gwen John, sem um tostão no começo do século, ganha dinheiro ao posar nua para Rodin e custear seus estudos. Paula Modersohn-Becker deixa seu marido artista na Alemanha para acompanhar o desenvolvimento da vanguarda em Paris. Suzanne Valadon descobre seu talento para o desenho e, incentivada pelos artistas para quem modelava, inicia uma nova carreira como artista. As brasileiras ]ulieta de França e Georgina de Albuquerque também buscam instrução na cidade luz, ainda que longe dos círculos vanguardistas, mas em atitude progressista se comparado as tradições brasileiras, onde arte não era considerado algo sério, mas coisa de mulher, e mulher 'amadora'.

Quando colocaram seus cavaletes ao lado dos homens nas aulas de arte, começaram a sentir que talvez também pudessem expressar suas preocupações, sua maneira de ver as coisas, que era definitivamente diferente. Há uma sensação de quebra de tabus à medida que o século começa. $A$ entrada acelerada das mulheres no mundo da arte na virada do século coincide com o nascimento da psicanálise, e certamente deve haver um elo entre o novo interesse no autoconhecimento e a repentina erupção dos autorretratos femininos. Mas não foi fácil. Os vanguardistas frequentemente enfatizavam uma presença servil de suas musas e a evidente disponibilidade física das mesmas, retratadas não poucas vezes como sexualmente subjugadas após o ato carnal. Em 1911, em pleno momento de manifestações pelo sufrágio, quando a ideia de independência feminina estava sendo debatida publicamente, o Grupo Camden Town optou por excluir as mulheres de seus membros por medo de 'diminuir a qualidade do grupo como um todo'. Em outro episódio, Walter Gropius, diretor da vanguardista escola Bauhaus, afirmou que as mulheres não eram fisicamente e geneticamente qualificadas para certas artes, já que pensavam em duas dimensões, em comparação 
com os parceiros masculinos, que poderiam fazê-lo em três (sic). Dessa maneira, foram os homens da Bauhaus que entraram para a história. Nomes como Klee, Kandinsky, László Moholy-Nagy seguem bem conhecidos, enquanto suas colegas foram esquecidas ou, na melhor das hipóteses, reconhecidas como "as esposas de".

Para combater o domínio masculino da cena literária e artística, muitas das mulheres modernistas que viviam na margem esquerda do rio Sena, em Paris no período entre guerras, formaram comunidades e amizades, que apoiavam o trabalho umas das outras. Elas leram na Académie des Femmes de Natalie Barney e publicaram com a também poetisa e editora Bryher ${ }^{5}$, através da Contact Editions. As comunidades de mulheres modernistas da década de 1920 em Paris revelam que as mulheres estavam desafiando o papel da musa e escrevendo, criando, pintando e fotografando, enquanto viviam em uma cultura sexista.

Mas o que significava para essas mulheres serem artistas dentro de um movimento de vanguarda que era comandado e representado por homens célebres e populares? Whitney Chadwick faz perguntas como essa em seu recente livro, Farewell to the Muse. Love, Warand the Women of Surrealism. Ela conta a experiência de mulheres artistas surrealistas, muitas das quais viviam em Paris durante esse período, e examina como essas mulheres se uniram para formar amizades e bases de apoio mútuo. Através de seus relacionamentos, elas encontraram espaço para criar e elaborar seu próprio trabalho, numa época em que seu valor como artista era ignorado, escarnecido ou oprimido por seus colegas contemporâneos masculinos. O livro de Chadwick cita uma visita e entrevista com Roland Penrose, artista, critico e historiador de arte, biografo de Picasso, que foi casado com Lee Miller e Valentine Penrose. Apesar de sua relação estreita com essas duas mulheres artistas, Penrose, já em idade avançada, desconsidera desdenhosamente suas carreiras artísticas, quando diz a Chadwick: "Você não deveria escrever um livro sobre as mulheres [...] elas não eram artistas [...] é claro que elas foram importantes, mas isso apenas porque elas eram nossas musas". 6

Finalmente, o advento da popularização da fotografia iria contribuir muito para as questões da autorrepresentação feminina. As câmeras reflex dos anos entre guerras eram frequentemente usadas em autorretratos como uma poderosa extensão do corpo. Em 1925, Cermaine Krull fotografa a si mesma com cigarro e câmera, um gesto clássico aplicável afinal a ambos os sexos, que resume brilhantemente a imagem do fotógrafo - e das fotógrafas - no entre guerras (FIC. 5).

\footnotetext{
5 A amplitude das contribuições de Bryher (nascida Annie Winifred Ellerman), para o desenvolvimento do modernismo como um movimento artístico, foi negligenciada, talvez por suas próprias ramificações políticas e de gênero. O papel de Bryher em assegurar a viabilidade de escritores e artistas modernistas começou a ser recuperado, graças a estudos de Jayne Marek, Susan McCabe e Charlotte Mandel.

6 Minha tradução. CHADWICK, 2017, p. 9.
} 
[Figura 05]

Germaine Krull. Autoportrait à

I'Icarette. 1925.

Foto: ๑ Centre Pompidou, MNAM-C-

$\mathrm{Cl}$, Dist. RMN-Grand Palais / centro de imagem Pompidou, MNAM-CCl.

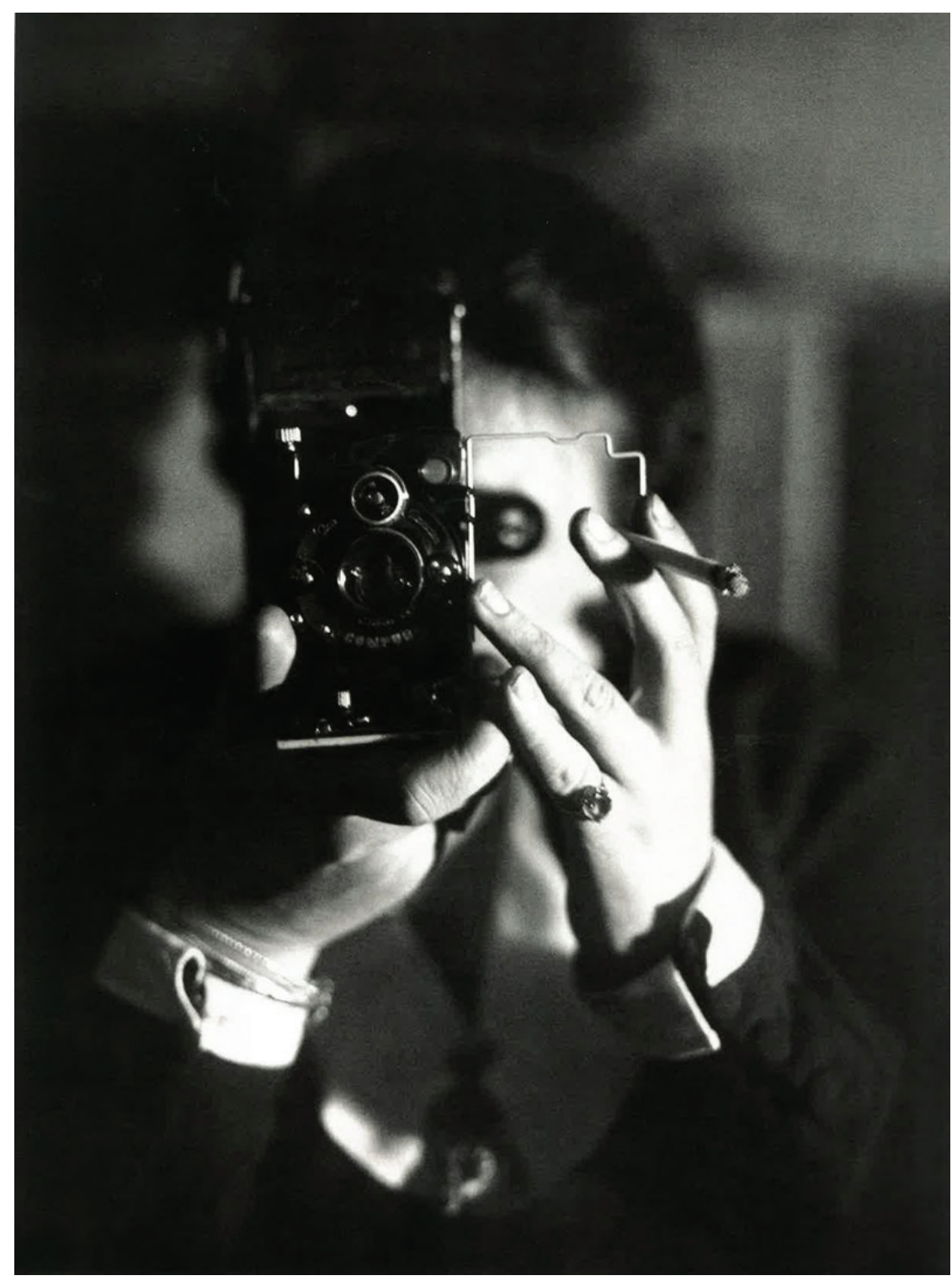

\section{Conclusão}

Desde o final dos anos 1960, com o surgimento das ondas feministas e do pós-estruturalismo, o autobiográfico foi reconfigurado como um local de discursos e definições sociais conflitantes e num valioso ponto de partida para o exame dos papéis construídos e mediados das mulheres, através de experiências pessoais. Questões de gênero, sexualidade e maternidade foram abordadas pelas mulheres por meio da autorrepresentação. Posições de masculinidades foram tratadas como paródia, feminilidades eram máscaras e excesso (criação social). A postura andrógina volta a surgir, redescobrindo artistas precursoras, como Claude Cahun. As políticas de representação e o envolvimento das mulheres com os discursos institucionais dentro das suas práticas artísticas oferecem um novo modelo de negociação dos domínios público/privado. 
Oferto esse artigo como uma oportunidade para considerarmos como as artistas usaram suas próprias imagens para explorar e expandir o ato de olhar, criando novos significados dentro da produção em arte. Ao fazê-lo, tornaram visíveis subjetividades complexas, multifacetadas, fragmentadas e diversas. Além disso, o autorretrato está implicado no complexo entrelaçamento dos papéis de sujeito e objeto que desempenhamos. O "autor" do autorretrato é sujeito e objeto. Para as mulheres, essa interação é particularmente distinta, podendo interferir e/ou redefinir seus papéis como sujeitos falantes de uma cultura masculina. Elas usaram o autorretrato também como subterfúgio, para dizer que estavam aqui, para inserir-se como praticantes dentro do mito masculinista do artista gênio. Elas não só desafiaram nossos olhares, como se reapropriaram de tropos convencionais da arte como costumeiramente a conhecemos.

\section{Referências bibliográficas}

BONNET, Marie-Jo. Femmes peintres à leur travail: de l'autoportrait comme manifeste politique (XVIIIe-XIXe siècles). Revue d'Histoire Moderne et Contemporaine, v. 3, n. 49, p. 140-67, 2002. Disponível em: <https://www.cairn.info/revued-histoire-moderne-et-contemporaine-2002-3-page-140.htm>. Acesso em: 02 dezembro 2019.

CHADWICK, Whitney. Farewell to the Muse: Love, War and the Women ofSurrealism. London: Thames \& Hudson Ltd, 2017. DUNCAN, Carol. Virility and Domination in Early Twentieth-Century Vanguard Painting. In: BROUDE AND GARRARD, Norma; Mary D. Feminism and Art History: Questioning the Litany. New York: Harper \& Row Publishers, 1982. p. 293 -315 .

NOCHLIN, Linda. Por que não houve grandes mulheres artistas?. São Paulo: Aurora, 2016.

POLLOCK, Griselda, Differencing the Canon: Feminist Desire and the Writing of Art's Histories, London, New York, Routledge, 1999.

SIMIONI, Ana Paula Cavalcanti; DIAS, Elaine. Mulheres artistas: as pioneiras (1880-1930). São Paulo: Pinacoteca do Estado, 2015.

WEEDON, Chris. Feminist Practice and Poststructuralist Theory. London: Blackwell, 1997. 